\title{
EDITORIAL
}

\section{A New International Forum on Gambling Issues}

There has been an unprecedented and explosive growth of legalized gambling opportunities within the Asia-Pacific region in the last decade. For example, soccer betting was regularized in Hong Kong in 2003, and sports betting will be legalized in Malaysia soon. The Macau casino gaming industry has flourished since the removal of a gaming monopoly in 2002. Macau, with a total of 33 casinos, is now famed as the 'Las Vegas of the East', earning huge revenue which since 2008 has exceeded that of the Las Vegas Strip. Recently, two integrated resort casinos opened in Singapore. To avoid exporting enormous economic benefits to neighboring areas, many Asian regions (e.g., Japan, Taiwan, China, Vietnam, Thailand, Cambodia and Korea) are keen to legalize or further expand casino gambling in the near future.

In addition to attractive gaming revenues and other economic opportunities, including a positive impact on tourism and the hospitality industry, gambling can have serious social and economic costs. These include problem and underage gambling, potential opportunities for loan sharks and money laundering, disrupted social relationships, bankruptcies, and suicides. It is important, therefore, that all key stakeholders should collaborate to ensure a balance between earning maximum revenue and minimizing any corresponding detrimental consequences. From a public health perspective, the development of responsible social policies is essential in addressing problems and potential harms associated with excessive gambling.

As a result, a group of people from different academic institutes and organizations are dedicated to the development of this platform, the Asian Journal of Gambling Issues and Public Health, as a vehicle for promoting discussion on gambling-related issues and gaming expansion, especially in Asia and the Pacific. The journal also aims to facilitate exchange of experience in gambling research, prevention, treatment and policy advocacy, across international jurisdictions. Scholars, experts and practitioners within and outside Asian regions are welcome to submit their manuscripts for review and publication in this journal.

This inaugural journal issue represents a fruitful cross-cultural collaboration in a shared mission of enhancing public health and reducing the negative social impact of problem gambling. This issue would never have been published without the contributors' hard work, and the unfailing support and advice from our honored international advisors, the members of the editorial board, and anonymous peer reviewers. Special thanks are due to Dr. Charles Chan, Dr. Rose van Es, Professor David Forrest, Professor 
Mark Griffiths, Professor Nerilee Hing, Professor Robert Ladouceur, Dr. Keis Ohtsuka, Professor Howard J. Shaffer and Professor Ming Ming Shen.

Last but not the least, the support and opinion of readers is extremely important. All readers are encouraged to send their comments and advice to us so that improvement can be made.

Larry Man Yum So Christine Xue Hong Wang Chief Editors 